\title{
Primary care physicians' approach to diagnosis and treatment of hepatitis $\mathbf{B}$ and hepatitis $\mathbf{C}$ patients Yildiz Peksen1, Sevgi Canbaz¹, Hakan Leblebicioglu*2, Mustafa Sunbul², Saban Esen ${ }^{2}$ and Ahmet Tevfik Sunter ${ }^{1}$
}

\author{
Address: ${ }^{1}$ Department of Public Health, Ondokuz Mayis University School of Medicine, Samsun, Turkey and ${ }^{2}$ Department of Infectious Diseases \\ and Clinical Microbiology, Ondokuz Mayis University School of Medicine, Samsun, Turkey \\ Email: Yildiz Peksen - ypeksen@omu.edu.tr; Sevgi Canbaz - sevgic@omu.edu.tr; Hakan Leblebicioglu* - hakanomu@omu.edu.tr; \\ Mustafa Sunbul - msunbul@omu.edu.tr; Saban Esen - sabanes@omu.edu.tr; Ahmet Tevfik Sunter - asunter@omu.edu.tr \\ * Corresponding author
}

Published: 06 February 2004

BMC Gastroenterology 2004, 4:3
Received: 03 September 2003

Accepted: 06 February 2004

This article is available from: http://www.biomedcentral.com/I47I-230X/4/3

(C) 2004 Peksen et al; licensee BioMed Central Ltd. This is an Open Access article: verbatim copying and redistribution of this article are permitted in all media for any purpose, provided this notice is preserved along with the article's original URL.

\begin{abstract}
Background: Infections caused by hepatitis $B$ virus (HBV) and hepatitis $\mathrm{C}$ virus $(\mathrm{HCV})$ are considered to be important health problems worldwide. The purpose of this study was to measure the general practitioners (GPs)' basic knowledge on HBV and HCV risk factors in determining their practice about this subject.
\end{abstract}

Methods: A cross-sectional type questionnaire survey was carried out at all of 32 primary healthcare centers (PHCCs) in Samsun, Turkey, between March I and April 3I, 2002. The questionnaires were sent to $160 \mathrm{GPs}$ and $129(80.6 \%)$ of them answered the questionnaires. Knowledge, role responsibility, self-efficacy and attitudes and beliefs regarding to viral hepatitis $B$ and hepatitis $\mathrm{C}$ were asked.

Results: Most of the GPs had adequate knowledge about transmission of HBV and HCV and also about risk factors for transmission of viruses. Most of the GPs (83.7\%) were aware of recommendations for approach to a baby, born from $\mathrm{HBsAg}$ positive mother. They have limited facilities in diagnosis of viral hepatitis. Of the participants, $108(83.7 \%)$ expressed that they could not diagnose HBV infections and $126(97.7 \%)$ of them stated that they could not make the diagnoses of $\mathrm{HCV}$ infection in their local healthcare centers. The knowledge about treatment of chronic viral hepatitis B $(21.8 \%)$ and C patients (17.8\%) with elevated ALT is not sufficient.

Conclusion: GPs' knowledge about risks of viral hepatitis was adequate in this study. They were not able to diagnose and follow up of these infections at PHCCs because of limited knowledge about chronic viral hepatitis and diagnostic facilities. GPs should be informed about current advice in diagnosis and treatment of chronic of HBV and HCV infections. 


\section{Background}

Infections caused by hepatitis B virus (HBV) and hepatitis $\mathrm{C}$ virus (HCV) are important health problems worldwide with a high morbidity and mortality [1-3]. It is known that 400 million people are HBV carriers and that each year 50 million people contact such a disease, resulting in 1-2 million deaths [3]. Infection with HCV occurs worldwide, the prevalence of antibody against HCV (anti-HCV) in serum in most developed countries range between 1\% to $2 \%$ [2]. It is also reported that currently 170 million people all over the world are infected with HCV infections and that $8000-10000$ people die from HCV infection and of complications per year $[4,5]$. Turkey, located in a region with moderate risk, has a prevalence in a range of $1.0 \%$ to $2.4 \%$ [6]. The prevalence of HCV infection was reported $1.5 \%$ in Turkey [7].

The hepatitis caused by HBV and HCV is extremely obscure. Symptoms appear only in $35.0 \%$ of those infected by HBV and in $25.0 \%$ of those infected by HCV. However, HBV and HCV are highly transmittable. Therefore, a decision made by World Health Organization (WHO) and National Institute of Health (NIH) suggests that all the patients should be examined with respect to their risk factors for HCV [8]. Turkey falls into the medium endemisity group in terms of $\mathrm{HBV}$ and $\mathrm{HCV}$ infection prevalence $[3,6]$. Such infections develop without any clear symptoms, so it is very important to carry good performance by the GPs in terms of diagnosis, treatment and follow up of patients. Therefore we attempted to evaluate the current practices, knowledge, attitudes of GPs regarding viral hepatitis B and C.

\section{Methods}

A cross-sectional study was carried out at all of 32 primary healthcare centers (PHCCs) in the central district of Samsun, Turkey between March 1 and April 31, 2002. The questionnaires were sent to all GPs $(n=160)$. One hundred and twenty-nine of $160(83.7 \%)$ GPs from different PHCCs completed the survey. The non-respondent GPs randomly distributed in PHCCs. The questionnaire was self-administered anonymously with an answer sheet. Questionnaire [see Additional file 1]. Question format ranged from closed questions with multiple choices to open comment and true/false type. Demographic variables such as gender, age and practice period in PHCCs were assessed. Also the information was collected regarding diagnostic facilities at PHCCs. The survey questionnaire includes a multiple-choice question relevant to sources of medical information. A question in medical knowledge about transmission of hepatitis viruses includes ten statements. GPs were asked to define these statements as correct or incorrect. This question was all marked out of 100 . Ten points were given for each correct choice the participants' marked and incorrect choice they left untouched. Participants were asked: "What would you suggest to do to protect an infant, born from a HBsAg positive mother?" The answers were: Injection of hepatitis B vaccine and hepatitis B immunoglobulin (HBIG), offering only hepatitis B vaccine, offering only HBIG, delivery by caesarean section and no knowledge about the problem. The participants were asked what they would suggest to do to protect an infant, born from an anti-HCV and HCV RNA positive mother with multi-choice question. The answers were as follows: There is not any preventive measure, injection of immunoglobulin, delivery by caesarean section, HCV does not transmit from mother to a baby and no knowledge about the problem.

Clinical practice was evaluated with the questions in the following: "What is the approximate number of individuals with acute or chronic viral hepatitis whom you diagnosed or followed up? Approximately how many individuals with acute or chronic viral hepatitis have you seen in the past 12 months?" Answers were obtained using fill-in-the-blank spaces.

Current knowledge about patient management based on four sample case presentations (below) was investigated with multi-choice answers.

\section{Sample Cases \\ Case-I}

A 35 years old woman with chronic hepatitis B admitted to a primary health care center. Her serum alanine aminotransferase (ALT) level was normal.

Case-II

A 40 years old man has been positive for HBsAg (+) for three years and two consecutive ALT results were $125 \mathrm{IU} /$ $\mathrm{L}$ and $120 \mathrm{IU} / \mathrm{L}$, respectively.

\section{Case-III}

A healthy/asymptomatic 55 years-old man admitted to a primary health care center. His alanine aminotransferase (ALT) level was elevated (150 IU/L) during check-up for life insurance; anti-HCV in ELISA was positive at subsequent work-up. He had a history of intravenous device that he used in 1963.

\section{Case-IV}

A healthy/asymtomatic 32 years-old woman admitted to a primary health care center. Her anti-HCV in ELISA was positive blood donation and ALT level was normal at subsequent work-up. She had no risk factors.

Shebab et al. [9] originally used the cases that were related to $\mathrm{HCV}$ in a survey. 
GPs were asked: What their next step would be, which additional test they would order, which treatment regimen they would recommend and if they would order a therapy recommended by a specialist, in the view of these cases.

In the text the results were given as means \pm standard deviations (SD).

\section{Results}

The questionnaire was completed anonymously, of the 160 surveys, $129(83.7 \%)$ were received and investigated using the data analysis.

\section{Demographic characteristics}

Of the study group, 72 (55.8\%) GPs were women and 57 $(44.2 \%)$ were men. The mean age of participants was 31.3 \pm 4.8 years. They had been in practice for $7.2 \pm 4.6$ years.

\section{Knowledge about transmission of $\mathrm{HBV}$ and $\mathrm{HCV}$}

Blood transfusion $(96.1 \%, 95.3 \%)$, blood and body fluids (95.3\%, 94. 6), sexual transmission (89.9\%, 89.9\%), intravenous drug use $(91.5 \%, 90.7 \%)$ and vertical transmission $(88.4 \%, 80.8)$ were listed as the most responsible risk factors for HCV and HBV, respectively, by the GPs.

When the participants were asked about their suggestions of how to protect an infant, born from a HBsAg positive mother, it was stated by $108(83.7 \%)$ of the participants that Hepatitis $\mathrm{B}$ vaccine should be injected to the infant during its delivery in addition to the immunoglobulin therapy. Twenty (15.5\%), $12(9.3 \%), 7(5.4 \%)$ and 7 (5.4\%) are the number of the given answers in 129 GPs for the following questions respectively; baby should be taken out by caesarean section, only immunoglobulin should be given at birth, only Hepatitis $B$ vaccine should be applied at birth and did not actually know what to do.

When the participants were asked about what they would suggest do to protect an infant, born from an anti-HCV and HCV RNA positive mother, it was stated by 67 $(51.9 \%)$ of them that there were no preventive measures to be taken during the birth and the baby should be followed with respect to HCV infection. Thirty-four (26.4\%), $33(25.6 \%)$ and $7(5.4 \%)$ of them suggested that immunoglobulin should be applied to the baby at birth, the birth should be carried out by caesarean section, and they aware not actually well informed about the case, respectively. The participants could choose more than one solution regarding protection of baby from viral hepatitis.

\section{Experience with viral hepatitis}

GPs reported that they had no diagnostic laboratory tests for HBV $(108 ; 83.7 \%)$ and HCV $(126 ; 97.7 \%)$. Because of the lack of diagnostic laboratory tests, these diseases could not be diagnosed at their PHCCs.

One hundred and ten (85.3\%) of the participants expressed that no patient with acute HBV (AHB) infection admitted to their health care centers and 84 (65.1\%) of them stated that they did not encounter any patient with chronic HBV (CHB) infection during the last 12 months. Rest of 45 GPs encountered total 52 patients at previous year; only 6 GPs examined more than one patient. One hundred and twenty-six (97.7\%) of them reported that they did not encounter any patient with HCV infection.

\section{Approach to sample cases}

Table 1 shows the criteria used by the participants in the management of the two cases with HBV infection.

Table 2 shows the criteria used by the participants in the management of the two cases with HCV infection.

\section{Sources of education}

The answers given by the participants about the sources of the updated current information for HBV and HCV infections were as follows, respectively: using journals: $63.6 \%$, $52.7 \%$, attending to congress: $14.0 \%, 11.6 \%$, using books: $79.1 \%, 76.7 \%$ and on-line sites: $3.1 \%, 3.1 \%$ (The sum of the answer is higher than the number of the participants for the participants checked more than one item.)

\section{Discussion}

Our data suggest that, the high response rate to our questionnaire indicated that GPs find the problem as an important area to consider. The sample was representative of GPs in Samsun region. The results could be extrapolated to whole Turkey on the basis of educational levels and working conditions, although the practice years of the respondents seem to be smaller than in practice.

HBV and HCV cause chronic viral hepatitis [10]. The frequency of the HBV and HCV infections are high in developing countries, including Turkey, especially young children who become infected with HBV are the most likely to develop chronic infection $[5,6,11]$. Therefore, GPs who constitute almost half of primary health care and outpatient services are expected to know basic knowledge on such infections. Furthermore, they are also supposed to guide their patients appropriately in terms of analysis of their diseases and treatment. GPs should be able to identify HBV and HCV high-risk groups at an early period because of the high importance of the complications like cirrhosis and hepatic failure $[6,9,12]$. The majority of GPs were well informed about transmission ways for HBV and HCV. However they identified sexual and vertical transmission as being important risk factors for HCV, the estimated transmission risk is only $5 \%$ [13]. This indicates 
Table I: Management of Patients with HBV

\begin{tabular}{|c|c|c|c|c|c|c|}
\hline & \multicolumn{3}{|c|}{ Case I } & \multicolumn{3}{|c|}{ Case II } \\
\hline & $\mathbf{n}$ & $\%$ & Current Advice & $\mathbf{n}$ & $\%$ & Current Advice \\
\hline \multicolumn{7}{|l|}{ At this point your next step would be to: } \\
\hline Follow in clinic: level of ALT & 53 & 41.1 & Yes & 19 & 14.7 & No \\
\hline Follow in clinic: refer if symptoms develop & 43 & 33.3 & Yes & - & - & No \\
\hline Refer to a specialist & 29 & 22.5 & No & 10 & 7.6 & Yes \\
\hline Don't know & 4 & 3.1 & & 100 & 77.5 & \\
\hline \multicolumn{7}{|l|}{$\begin{array}{l}\text { Which additional tests would you order } \\
\text { (check all that apply)*: }\end{array}$} \\
\hline HBV-DNA by PCR ${ }^{* *}$ & 79 & 61.2 & No & 62 & 48.1 & Yes \\
\hline HBV genotyping & 2 & 1.6 & No & 16 & 12.4 & No \\
\hline Liver biopsy & 93 & 72.1 & No & 44 & 34.1 & Yes \\
\hline Don't know & - & - & & 2 & 1.6 & \\
\hline \multicolumn{7}{|l|}{$\begin{array}{l}\text { If you order therapy, which regimen would } \\
\text { you recommend: }\end{array}$} \\
\hline Lamivudine & 40 & 31.0 & No & 26 & 20.2 & Yes \\
\hline IFN- $\alpha+$ Lamivudine & 3 & 2.3 & No & - & - & Yes \\
\hline Interferon (IFN)- $\alpha$ & 11 & 8.5 & No & 2 & 1.6 & Yes \\
\hline Don't know & 75 & 58.2 & & 101 & 78.2 & \\
\hline
\end{tabular}

* The sum of the answer is higher than the number of the participants for the participants checked more than one item. ** Polymerase Chain Reaction (PCR)

confusion between modes of transmission for HBV and HCV. The relatively poorer levels of knowledge about transmission of HCV obtained in this study may also be found in the general population. Therefore strategic programmes of health education and awareness rising to both professionals and public are recommended.

Up to $90 \%$ of infants of highly infected with HBsAg and HBeAg positive mothers become HBV carriers compared with $10 \%$ to $40 \%$ of babies born anti-HBe positive mothers. HBV vaccine and HBIG should be applied at birth to the baby born to a HBsAg positive mother [14]. Due to the data gathered at the end of these studies the transmission is not effected by the way of the baby delivery and breastfeeding. Since the frequency of vertical transmission is less than $5 \%$, there was no special recommendation for antiHCV positive pregnant women $[13,15,16]$. This study shows that most GPs are practicing within current recommendations regarding hepatitis $\mathrm{B}$ immunization of infants, but the use of vaccine and HBIG at birth may not provide an effective safety in preventing perinatal HBV transmission if screening for HBsAg is not performed universally. However most of them $(83.7 \%$ and $97.7 \%$, respectively) were unable to diagnose the $\mathrm{HBV}$ and $\mathrm{HCV}$ infections in PHCCs due to the lack of laboratory facilities. Most of the participants pointed out that they had not determined or followed up of any patient with HBV and HCV infections at their health care centers during the last 12 months. This fact clearly shows that PHCCs in Turkey are saw insufficient in terms of the determination of the patients with HBV and HCV infections and their follow up. These results underscore the need of effective mechanisms in place and on time for immunoprophylaxis to infants born to HBsAg positive women.

We identified gaps between the knowledge about appropriate use of diagnostic tests and interventions important to identify patients with chronic hepatitis and to make treatment decision. In case I; she has a normal ALT, HBVDNA testing and liver biopsy should not be recommended $[17,18]$. However $61.2 \%$ of the respondents ordered HBV DNA test and $72.1 \%$ liver biopsy in case I. Forty-eight point one percent of the GPs stated HBV DNA test and $34.1 \%$ liver biopsy in case II. The EASL consensus statement recommended liver biopsy and consideration for treatment in case II and regular follow up at six-month interval with determination of ALT level, no further testing to confirm the diagnosis of chronic HBV infection in case I [17], but most of the participants did not differentiate these two entities. In case III and IV, respondents would unnecessarily repeat the anti-HCV test. These finding suggest that inappropriate use of tests for viral hepatitis may lead to misdiagnosis, unnecessary testing, and also over-treatment.

As long as ALT levels are normal, the treatment is not required even if PCR HBV DNA or HCV RNA is found to be positive $[17,19]$. However $41.8 \%$ and $37.2 \%$ of GPs support to treat chronic hepatitis $\mathrm{B}$ and $\mathrm{C}$ patients with normal ALT, respectively. When asked about the treatment for $\mathrm{HCV}$, only $17.8 \%$ of respondents recommended combined interferon and ribavirin therapy to treat the 
Table 2: Management of Patients with HCV

\begin{tabular}{|c|c|c|c|c|c|c|}
\hline & \multicolumn{3}{|c|}{ Case III } & \multicolumn{3}{|c|}{ Case IV } \\
\hline & $\mathbf{n}$ & $\%$ & Current Advice & $\mathbf{n}$ & $\%$ & Current Advice \\
\hline \multicolumn{7}{|l|}{ At this point your next step would be to: } \\
\hline Repeat the measurement of anti-HCV & 16 & 12.4 & No & 49 & 38 & No \\
\hline Follow in clinic: refer if symptoms develop & 5 & 3.9 & No & 30 & 23.2 & Yes \\
\hline Refer to a specialist & 108 & 83.7 & Yes & 50 & 38.8 & Yes \\
\hline Don't know & - & - & & - & - & \\
\hline \multicolumn{7}{|l|}{$\begin{array}{l}\text { Which additional tests would you order } \\
\text { (check all that apply)*: }\end{array}$} \\
\hline anti-HCV ELISA & 52 & 40.3 & No & 50 & 38.8 & No \\
\hline anti-HCV RIBA & 2 & 1.6 & Yes & 4 & 3.1 & Yes \\
\hline HCV-RNA by PCR & 105 & 81.4 & Yes & 106 & 82.2 & Yes \\
\hline HCV genotyping & 3 & 2.3 & No & 9 & 7.0 & No \\
\hline \multicolumn{7}{|l|}{$\begin{array}{l}\text { If you order therapy, which regimen } \\
\text { would you recommend: }\end{array}$} \\
\hline IFN- $\alpha$ for 6 months & 23 & 17.8 & No & 20 & 15.5 & No \\
\hline IFN- $\alpha$ for 12 months & 4 & 3.1 & No & 4 & 3.1 & No \\
\hline Ribavirin alone & - & - & No & - & - & No \\
\hline IFN- $\alpha$ and Ribavirin & 23 & 17.8 & Yes & 24 & 18.6 & No \\
\hline Don't know & 79 & 61.3 & & 81 & 62.8 & \\
\hline
\end{tabular}

* The sum of the answer is higher than the number of the participants for the participants checked more than one item.

chronic hepatitis C patients with elevated ALT in case III. Twenty-one point eight percent of them recommended either IFN- $\alpha$ or lamivudine to treat chronic viral hepatitis $B$ in case II. The remainder GPs did not actually know what to do with such patients. Therefore the knowledge of treatment options in chronic hepatitis $\mathrm{B}$ and $\mathrm{C}$ is poor, this may decrease the ability to accurately assess patients and initiate therapy. This clearly identifies that regular updates on current treatments are needed. Protocols, reviews and consensus reports have been useful in the management of chronic viral hepatitis [17-19].

General practitioners reported medical books and journals to be the most useful source of information regarding viral hepatitis but were concerned about inadequate timely access the journal and also the low rate of obtaining information from on-line sites. However internet may be a solution for difficulties and delays in obtaining relevant information. Most of the updated guidelines and consensus reports could be easily and freely accessible at on-line sites such as http://www.jhep-elsevier.com and http://consensus.nih.gov/cons/116/ 116cde intro.htm $[17,19]$.

\section{Conclusion}

As the "gatekeepers" to the health care system, GPs carry out significant missions in PHCCs where primary protective and curative health services are held out. It is, therefore necessary to completely inform GPs of common health problems as well as of the ways of their solutions.
In order to prevent HBV and HCV infections, GPs drive great responsibility of the diagnosis and treatment of the infected patients as well as their follow up. This study demonstrates high awareness of the transmission of viral hepatitis and high-risk groups among GPs but also considerable knowledge gaps about the timing of ordering diagnostic tests and treatment recommendations. Results suggest several opportunities for improvement. Efforts to educate the GPs about the appropriateness and importance of identification of HBV and HCV infection during post-graduation period should be improved. PHCCs should be technically supported to ease the diagnosis of HBV and HCV infections. Finally further coordination between an advanced health care center and specialists should be established to enable such infections to be followed up in PHCCs.

\section{Competing interests}

None declared.

\section{Authors' contributions}

YP participated in the design and coordination of the study, SC drafted the questionnaire and participated in study design and coordination. HL conceived the study, particated in its design and drafted the manuscript. MS and SE provided clinical expertise in interpretation of data and drafting manuscript. ATS provided drafted the manuscript and performed the statistical analysis. All authors read and approved the final manuscript. 


\section{Additional material}

\section{Additional File 1}

Viral Hepatitis Questionnaire. A questionnaire to evaluate the current practices, knowledge, attitudes of general practitioners regarding viral hepatitis $B$ and $C$.

Click here for file

[http://www.biomedcentral.com/content/supplementary/1471230X-4-3-S1.doc]

\section{References}

I. Chen DS: From hepatitis to hepatoma: lessons from type B viral hepatitis. Science 1993, 262:369-370.

2. Di Bisceglie AM: Hepatitis C. Lancet 1998, 35 I:35I-355.

3. Lee WM: Hepatitis B virus infection. N Engl J Med 1997, 337:1733-1745.

4. Alter MJ: Epidemiology of hepatitis C. Hepatology 1997, 26:62S-65S.

5. Global surveillance and control of hepatitis C. Report of a WHO Consultation organized in collaboration with the Viral Hepatitis Prevention Board, Antwerp, Belgium. J Viral Hepat 1999, 6:35-47.

6. Hepatitis C--global prevalence (update). Wkly Epidemiol Rec 2000, 75:18-19.

7. Thomas DL, Mahley RW, Badur S, Palaoglu E, Quinn TC: The epidemiology of hepatitis C in Turkey. Infection 1994, 22:4I I-4I4.

8. Recommendations for prevention and control of hepatitis $\mathbf{C}$ virus (HCV) infection and HCV-related chronic disease. Centers for Disease Control and Prevention. MMWR Recomm Rep 1998, 47:1-39.

9. Shehab TM, Sonnad SS, Lok AS: Management of hepatitis C patients by primary care physicians in the USA: results of a national survey. J Viral Hepat 200I, 8:377-383.

10. Ryder SD, Beckingham IJ: ABC of diseases of liver, pancreas, and biliary system: Chronic viral hepatitis. BMJ 200I, 322:219-22I.

11. Chang MH: Natural history of hepatitis B virus infection in children. J Gastroenterol Hepatol 2000, I5 Suppl:EI6-EI9.

12. Fattovich G: Natural history and prognosis of hepatitis B. Semin Liver Dis 2003, 23:47-58.

13. Effects of mode of delivery and infant feeding on the risk of mother-to-child transmission of hepatitis $C$ virus. European Paediatric Hepatitis C Virus Network. BJOG 200I, 108:37I-377.

14. Sexually transmitted diseases treatment guidelines 2002 . Centers for Disease Control and Prevention. MMWR Morb Mortal Wkly Rep 2002, 5 I: I-78.

15. Dal Molin G, D'Agaro P, Ansaldi F, Ciana G, Fertz C, Alberico S, Campello C: Mother-to-infant transmission of hepatitis $\mathbf{C}$ virus: rate of infection and assessment of viral load and IgM anti-HCV as risk factors. I Med Virol 2002, 67:137-142.

16. Zanetti AR, Tanzi E, Newell ML: Mother-to-infant transmission of hepatitis C virus. J Hepatol 1999, 3 I Suppl I:96-100.

17. EASL International Consensus Conference on Hepatitis B. 13-14 September, 2002: Geneva, Switzerland. Consensus statement (short version). J Hepatol 2003, 38:533-540.

18. Chongsrisawat V, Poovorawan Y: Management of chronic hepatitis B and C virus infections. Indian J Pediatr 2002, 69: I49-154.

19. National Institutes of Health Consensus Development Conference Statement: Management of hepatitis C: 2002--June 10-1 2, 2002. Hepatology 2002, 36:S3-20.

\section{Pre-publication history}

The pre-publication history for this paper can be accessed here:

http://www.biomedcentral.com/1471-230X/4/3/prepub

Publish with Bio Med Central and every scientist can read your work free of charge

"BioMed Central will be the most significant development for disseminating the results of biomedical research in our lifetime. "

Sir Paul Nurse, Cancer Research UK

Your research papers will be:

- available free of charge to the entire biomedical community

- peer reviewed and published immediately upon acceptance

- cited in PubMed and archived on PubMed Central

- yours - you keep the copyright

Submit your manuscript here:

http://www.biomedcentral.com/info/publishing_adv.asp
BioMedcentral 